\title{
Pressing Issues in College Counseling: A Survey of American College Counseling Association Members
}

Timothy B. Smith

Brigham Young University, tbs@byu.edu

Brenda Dean

Suzanne Floyd

Christopher Silva

Momoko Yamashita

See next page for additional authors

Follow this and additional works at: https://scholarsarchive.byu.edu/facpub

Part of the Counseling Psychology Commons

\section{Original Publication Citation}

Smith, T. B., Dean, B., Floyd, S., Silva, C., Yamashita, M., Durtschi, J., \& Heaps, R. (2007). Pressing issues in college counseling: A survey of American College Counseling Association members. Journal of College Counseling, 10, 64-78.

\section{BYU ScholarsArchive Citation}

Smith, Timothy B.; Dean, Brenda; Floyd, Suzanne; Silva, Christopher; Yamashita, Momoko; Durtschi, Jared; and Heaps, Richard A., "Pressing Issues in College Counseling: A Survey of American College Counseling Association Members" (2017). Faculty Publications. 2002.

https://scholarsarchive.byu.edu/facpub/2002

This Peer-Reviewed Article is brought to you for free and open access by BYU ScholarsArchive. It has been accepted for inclusion in Faculty Publications by an authorized administrator of BYU ScholarsArchive. For more information, please contact ellen_amatangelo@byu.edu. 


\section{Authors}

Timothy B. Smith, Brenda Dean, Suzanne Floyd, Christopher Silva, Momoko Yamashita, Jared Durtschi, and Richard A. Heaps 
Running Head: NATIONAL SURVEY OF COLLEGE COUNSELING

Smith, T. B., Dean, B., Floyd, S., Silva, C., Yamashita, M., Durtschi, J., \& Heaps, R. (2007). Pressing issues in college counseling: A survey of American College Counseling Association members. Journal of College Counseling, 10, 64-78.

Pressing Issues in College Counseling:

A Survey of American College Counseling Association Members

Timothy B. Smith, Brenda Dean, Suzanne Floyd, Christopher Silva, Momoko Yamashita, Jared Durtshi, and Richard Heaps

Brigham Young University 


\begin{abstract}
The authors conducted a survey of members of the American College Counseling Association to ascertain the experiences and opinions of college counselors on several pressing issues within the profession. Survey results with 133 respondents indicated that counseling centers may benefit from increasing the number of group counseling interventions, by increasing the multicultural competence of services provided, by implementing crisis/disaster mental health initiatives, and by more effectively consulting with other professionals across campus.
\end{abstract}




\section{Pressing Issues in College Counseling:}

\section{A Survey of ACCA Members}

Counselors working in university and college counseling centers need to continually adapt to trends in higher education and in social science research. Over the past several years, recommendations and guidelines for improving the quality of college counseling services have been provided by several authors (Bishop, 1990, 2006; Cooper, 2003; Davis \& Humphrey, 2000; Hodges, 2001; Stone \& Archer, 1990). These authors have been consistent in the themes emphasized, including the need to adequately address (1) the apparent increasing average severity of clients’ presenting conditions, (2) increased workloads and administrative pressures to “do more with less,” (3) the need to market the usefulness of counseling center services on campus (i.e., collaboration and networking with other campus offices), (4) multicultural competence of services, and (5) crisis management services and disaster mental health. Issues such as these have shaped much of the discussion in the field over the past two decades. Although there is currently some evidence that many counseling centers are responding adequately to these issues (Guinee \& Ness, 2000), there is also evidence that more needs to be done (e.g., Davidson, Yakushka, \& Sanford-Martens, 2004). To ascertain current practices, we conducted a survey of college counseling professionals regarding issues identified in the literature as being the most pressing. These issues are highlighted briefly in the following paragraphs.

\section{Severity of Client Symptoms}

A concern frequently cited in the literature over the past two decades is the apparently increasing severity of mental health symptoms presented by clients in college counseling centers (e.g., Benton, Robertson, Tseng, Newton, \& Benton, 2003; Bishop, 2006; Erdur-Baker, Aberson, Barrow, \& Draper, 2006). Although this apparent trend may be due to several confounding factors, such as the increased use of psychotropic medication among college students, one consequence of the trend has been an increase in the demand for counseling center services. As a result, college counseling centers 
have had to implement a variety of such procedures as session limits, waiting lists, and psychiatric consultation, which are characteristic of community mental health agencies that happen to be located on college campuses (Rudd, 2004).

Institutional Pressures and Workloads

Paradoxically, as counseling center resources appear to be in greater demand, fiscal and administrative policies for student services in higher education institutions have become more conservative. Institutions of higher education have moved toward increased accountability, which requires increased workload to generate required data and reports. In short, many counseling centers have been asked to “do more with less,” a dynamic which creates significant challenges (e.g., Bishop, 1990). We therefore felt it important to ascertain the average workloads and current job satisfaction of college counselors and to ask how they have adapted practices to handle increased demands for services (Bishop, 2006).

\section{Collaboration and Advocacy across Campus}

College and university administrators may sometimes make decisions that adversely affect the quality of counseling services provided to students (e.g., Kiracofe, 1993). Therefore, college counselors have been encouraged to advocate in behalf of student well-being, using empirical data and effective consultation skills to demonstrate the utility of counseling services on campus (Cooper, 2003; Ellingson, Kochenour, \& Weitzman, 1999; Stone \& Archer, 1990). College counselors are in a position to positively impact many aspects of campus life, from consulting with campus health center physicians about mental health issues (Rudd, 2004), to increasing the effectiveness of academic advising (Coll \& Stewart, 2002), to facilitating international students’ adjustment to their new environment (Mori, 2000). Yet the degree to which college counselors are reaching out to other campus entities remains unknown. We therefore evaluated the frequency with which college counselors work with personnel from other offices on campus. 


\section{Multicultural Competence}

Another oft-repeated theme in the professional literature concerns the need for multicultural competence in service provision (Bishop, 1990; Davis \& Humphrey, 2000; Hodges, 2001; Stone \& Archer, 1990). Literally hundreds of publications have appeared in the past decade that provide specific guidelines for adapting treatments, policies, and procedures to better meet the needs of clients of color (e.g., Arredondo et al., 1996; Wright, 2000). Given such a strong emphasis on multicultural competence in providing services, we sought to determine the degree to which college counselors report changes in their center's policies or practices to better meet the needs of multicultural students.

\section{Crisis Planning and Disaster Mental Health}

In addition, many authors have advocated that college counselors become better prepared to provide crisis counseling and effective disaster response services (e.g., Lee \& Casey, 2004; Ottens \& Black, 2000; Schwitzer, 2003). However, it appears that the sudden increase in attention to crisis management and disaster mental health immediately following the terrorist attacks of September 11, 2001 may not have produced systematic implementation or on-going efforts to maintain adequate preparations in this area. Therefore, we also desired to evaluate the crisis and disaster response practices that college counselors currently perceive as being typical of their counseling center. Purpose of the Present Study

Although the issues described above are apparently among the most important in the field, all except disaster mental health were emphasized at least 16 years ago (i.e., Stone \& Archer, 1990); they are no longer new issues. Survey research can be useful in documenting progress toward professional objectives and in identifying areas in need of additional improvement.

We also sought to collect information distinctive from that obtained in previous national surveys of college counseling. For example, the National Survey of Counseling Center Directors (Gallagher, Zhang, \& Taylor, 2003) is conducted annually with counseling center directors but does 
not represent the experiences of counselors without administrative roles. We therefore felt it essential to evaluate the opinions of counselors actually engaged in service provision and to explicitly contrast their experiences with those of counseling center administrators. We were particularly interested in evaluating college counselors whose training and professional identity are associated with the field of counseling (i.e., affiliation with the American Counseling Association) who have not been targeted in previous national surveys. We were also interested in gathering information not evaluated previously, such as counselors' frequency of contact with other campus offices and counseling centers' disaster mental health preparedness. Furthermore, we were aware that previous national surveys of college counselors have consisted primarily of rating scales that do not allow respondents to raise their own concerns. We therefore felt it essential to ask counselors open-ended questions regarding their own opinions about the profession, including aspects of their counseling center operation and graduate student professional preparation that are in need of improvement. The overall purpose of the present study was to provide information about counselors’ current work experiences in college counseling centers with respect to several of the most pressing issues in the profession.

\section{Method}

We mailed surveys to a randomly selected subset of 450 professional members of the American College Counseling Association (ACCA). ACCA student members, retired members, and members with addresses outside of the United States were excluded from the mailing. A total of 133 individuals responded to the survey (30\% return rate). Participants consisted of 86 women (65\%) and 47 men (35\%). The average age of respondents was 48.4 years, with a range of 26 to 66 years. Most participants were European American (88\%), with 5\% being Hipanic/Latino(a) American, and less than 2\% in each of the categories of African American, Asian American, or multi-racial. Most participants (58\%) were master's level professionals, with $40 \%$ being doctoral level and $2 \%$ being 
bachelor's level. Of the total sample, $45 \%$ had some administrative component to their employment position (e.g., counseling center director or associate director).

The survey consisted of several questions to ascertain participants’ demographic information, professional employment, accompanying responsibilities, and opinions about the pressing professional issues described in the previous section (client severity, collaboration across campus, workload and job satisfaction, etc.). Questions regarding client severity and counselor workload required respondents to fill in relevant percentages and numbers of hours (e.g., percentage of work week spent on administrative activities, number of hours spent providing individual counseling). Likert-type scaling was used to evaluate job satisfaction $(1=$ very low, 9 = very high $)$ and frequency of collaboration with other campus organizations $(1$ = never, 2 = rarely, 3 = quarterly, 4 = monthly, 5 = bi-monthly, $6=$ weekly, 7 = daily).

Seven questions requiring open-ended responses addressed the pressing issues of multicultural competence, crisis planning and disaster mental health, etc. Responses to these seven open-ended questions were analyzed using standard qualitative content analysis procedures (Denzin \& Lincoln, 2000), as follows. After an initial reading of the survey questions, coders developed tentative content categories, which were then operationally defined and organized in table format. The tentative categories were then reformulated as needed to more accurately reflect the meaning of the content in the participants' responses. This refining process of category reformulation was repeated several times in order to avoid inconsistencies and discrepancies. The coded material was then reviewed by a second coder who (1) verified that the categories were conceptually meaningful and distinct, (2) searched for additional meaning in participants' responses that had not yet been covered by an existing category, and (3) verified that the coding performed was accurate. Disagreements among coders were resolved by discussion reaching eventual consensus. 
Results

Severity of Client Symptoms

Two survey questions requested participants to estimate the percentage of their clients who (1) experience severe distress, such as suicidal intention, panic attacks, etc., and (2) experience mental health conditions that are so debilitating that they would be unable to remain enrolled as students without ongoing counseling services. Across all participants providing counseling services, caseloads were found to consist of an average of $36 \%$ of clients experiencing severe distress, which proportion is similar to that reported elsewhere (Gallagher et al., 2003). Half of the clients reported to have severe distress (18\% of the total number of clients) had conditions so severe that they were deemed unlikely to remain in school without mental health counseling. However, these data are greatly limited because they are based upon counselors’ perceptions, rather than on reliable measurements of symptom severity.

Counselor Workload and Job Satisfaction

Participants reported the percentage of their work hours devoted to direct services, indirect services, administrative work, and other activities. Participants also reported the number of hours that they provide individual counseling services, group counseling services, and outreach services/programs. These reports were tallied separately for counselors and counseling center administrators (Table 1); 25 participants without counseling responsibilities were excluded from these analyses.

As can be seen in Table 1, counselors reported spending an average of $62 \%$ of their work time providing direct services to clients, with an average of 24.1 hours being spent in providing individual and group counseling. When direct and indirect service activities were combined, counselors reported spending $80 \%$ of their total time providing services to clients. In contrast, counseling center administrators in our survey reported spending $62 \%$ of their time providing direct and indirect services 
for clients and the remaining $38 \%$ of their time on administrative activities. Thus the difference between counselors and administrators in the amount of time they devote to service provision vs. administrative activities was calculated at $18 \%$ in this sample, corresponding to an approximate value of 7.2 hours in a 40 hour work week. This value was also similar to the reported 7.6-hour difference between counselors and administrators in the average number of reported hours spent providing individual and group counseling services. Thus the time allocated for counseling center administration appears to replace direct service hours rather than indirect service hours.

Participants’ ratings of their job satisfaction were quite high, with an average of $7.7(\mathrm{SD}=1.3)$

on a 9-point scale. All but 15\% of participants rated their level of satisfaction in the high range, corresponding with a score of 7 or above. This finding provides an important context for interpreting survey findings regarding workload: Despite challenges and pressures that college counselors may face, they generally enjoy their work.

\section{Collaboration Across Campus}

Given the emphasis in the professional literature on the importance of consultation and outreach activities (e.g., Cooper, 2003; Stone \& Archer, 1990), our survey evaluated the frequency of collaboration between counselors and personnel from other campus offices. Participants rated the frequency with which they work with several different types of professionals across campus; average ratings and their scale equivalents are found in Table 2.

To determine differences in the rates of counselor contact across the several types of campus offices considered, we conducted a repeated measures multivariate analysis of variance. The results were statistically significant $(F=21.4, p<.0001)$, with post-hoc analyses indicating that participants had equivalent levels of contact $(p>.20)$ with professors/instructors, college/university administrators, and academic advisors. Compared with these kinds of contact, participants reported lower frequency of interactions ( $p<.01$ for all comparisons) with personnel from multicultural student services, 
disability/accessibility services, and health/medical services, with no differences in their level of association among them $(p>.10)$. Participants showed a significantly lower frequency of contact with personnel associated with international student services than with all other kinds of campus services ( $p$ $<.001$ for all comparisons).

Open-ended Responses to Questions about Key Issues in College Counseling

Participants responded to seven open-ended questions; the corresponding categories of responses are summarized in Table 3. Narrative summaries of the responses to each question are provided in the following paragraphs.

Strategies for meeting increasing demands for services. In response to a question about how counseling centers are meeting the increasing demand for counseling services (e.g., caseload, pressures to see more clients), only $4 \%$ responded that caseload demand is not a problem. The most common response (26\%) was that counseling centers need more employees. Although some universities may have the resources to simply increase the number of counseling center staff to accommodate a growing caseload, many do not. Therefore, the remaining responses appeared more practical: waiting lists (17\%), session limits (16\%), referrals to other resources (10\%), and group sessions (9\%). Several respondents (14\%) indicated taking on additional caseload without making any adaptations in the center's policies or practices, and $4 \%$ said that their centers allow individual counselors to determine how to handle their caseload. These last two kinds of responses, although egalitarian, seem to be precursors to counselor burnout (Stone, 1988).

Administrative support. Respondents were asked how their counseling centers were generating support among school officials. Many (33\%) stated that they meet with administrative committees to inform them about current issues and needs. Some counselors (23\%) indicated that they gather data and provide formal reports regarding counseling center activities. A few (14\%) attempt to increase counseling center visibility on campus through explicit involvement in student service 
organizations/activities. Although many counselors do network with school administrators, 30\% admitted taking no actions to increase administrators’ support for counseling services. This finding underscores the importance of repeated appeals in the literature for college counselors to advocate with school officials and to actively demonstrate the utility of counseling services on campus (Bishop, 1990; Cooper, 2003; Davis \& Humphrey, 2000; Ellingson et al., 1999; Spriggs, 2005).

Multicultural competency. According to survey participants, the most common strategy employed at the counseling centers to increase the multicultural competence of services is to provide workshops or in-service training for counseling center employees (44\%). Other counselors (22\%) described recruiting a racial/ethnic minority staff member (or intern) or hiring a particular staff member with expertise in multicultural issues. Several counselors (22\%) replied that they work regularly with the multicultural student office at the university, and some (11\%) provide outreach programs targeting multicultural students on campus. A single participant (1\%) indicated that the counseling center had changed many policies and practices in order to better meet the needs of multicultural students on campus.

Crisis counseling and disaster mental health response. Regarding approaches used to meet crisis/disaster mental health incidents or needs, many participants (33\%) said that although preliminary steps have been taken, nothing formal has been developed. Only one quarter (26\%) of counselors indicated that their center has implemented a clearly defined crisis/disaster response plan and has in place systems to handle crises/disasters on campus. A few respondents (19\%) said that counseling center employees receive specialized training to handle those types of situations, but they provided no details regarding center policies or practices. Surprisingly, several respondents (14\%) reported that there are no formal policies or practices in their counseling center to handle on-campus crises/disasters, and several others (7\%) said that the counseling center has no involvement in crisis/disaster planning because some other office on campus handles all emergency situations. These last two types of 
responses (totaling 21\%) are counter-intuitive, given counselors’ abilities and training that could greatly facilitate responses to a crisis/disaster affecting the campus.

Psychotropic medication. The increased numbers of college students taking psychotropic medications has impacted counseling centers in a variety of ways. Most often, this trend has resulted in counselors engaging in case consultations with medical professionals (30\%), with a few centers (7\%) having hired psychiatrists. Counselors commented that medications appear to have increased students’ capacity to remain enrolled in college (17\%), with accompanying increases in the severity of mental health symptoms among students (13\%), but with some respondents noting that students may seek out and rely on medications more than on counseling (9\%). A few counselors (7\%) indicated that their counseling center has changed its intake and evaluations to more thoroughly assess medication history.

Areas for improvement in counselor education programs. A survey question asked which content areas counselors would like to have learned more about in their graduate education, given their current job responsibilities (e.g., Bishop, 2006). Topics mentioned were multicultural issues (19\%), crisis/disaster mental health issues (12\%), spirituality and religious issues (12\%), higher education issues (12\%), legal/ethical issues (8\%), and substance abuse counseling (4\%). In addition, some counselors (19\%) expressed a desire for more applied experience during their graduate training. Others (15\%), likely current administrators, indicated a need to learn organizational/managerial skills. Counselor education programs could consider this feedback as they modify curricula.

Desired improvements in counseling centers. A final question asked what the counselors most desired to improve about the counseling center in which they work. The most frequent answers were straightforward: increase the amount of resources (30\%) and the number of staff (28\%). Other responses (20\%) suggested that the counseling center needed to establish better connections with other institutions, with students, and with the community. Several counselors (11\%) expressed desires for improved professionalism/collegiality among the counselors in the center and for improved quality of 
the services provided (9\%). A few people (3\%) said they would like to have more time for individual counseling sessions. Overall, the responses to this question did not indicate major crises in the workplace.

\section{Discussion}

The results of this study present a perspective for the college counseling profession. Respondents indicated high satisfaction with their positions, although results showed notable variability in what their assignments entail. Almost half of the participants in this particular survey had administrative responsibilities in addition to providing direct services to student clients. Overall, the results of this survey provide insights regarding several pressing issues in the profession, as discussed in the following paragraphs.

\section{Severity of Client Symptoms}

The survey results indicated that approximately one-third of college counseling center clients experience major emotional distress. The magnitude of this proportion greatly qualifies the frequently cited research regarding the increasing severity of client problems (e.g., Benton et al., 2003; ErdurBaker et al., 2006; Rudd, 2004). Even though mental health concerns may have increased in severity compared with concerns of several decades ago (prior to the widespread use of psychotropic medication), college counselors still see a large percentage of clients with difficulties of mild to moderate severity. Therefore, although college counseling center administrators should be vigilant in adapting their policies, services, and referral networks to effectively meet the needs of students with severe and/or chronic conditions, they certainly do not yet need to embrace all practices characteristic of community mental health clinics. Rather, in conjunction with other student services they may remain focused on developmentally appropriate services in support of well-being across campus. 
Many publications have highlighted increasing institutional pressures for counseling centers to increase the number of services provided to students (e.g., Kiracofe, 1993). Our survey indicated that on average college counselors spend about $60 \%$ of their work hours providing direct services, which percentage does not appear to be excessive. Most direct service hours are spent in individual counseling, with an average of less than one hour per week spent in group counseling interventionsabout 3\% of total direct service hours. If pressures to see more clients are indeed problematic, then increasing the average time that counselors spend in group interventions by only 2 hours per week could potentially increase the overall number of clients served each week by 20\% (assuming 6 clients per 2-hour group session).

The sparse use of group counseling interventions may be attributed to difficulties in obtaining sufficient numbers of consistent participants in campus settings (Parcover, Dunton, \& Gehlert, 2006). However, because group counseling has been shown to be just as effective as individual counseling (McRoberts, Burlingame, \& Hoag, 1998) and because greater numbers of clients can be accommodated in group counseling than in individual counseling, increasing referrals to group counseling interventions may provide a viable solution for counseling centers experiencing pressure to see additional clients (Golden, Corazzini, \& Grady, 1993). Future efforts are needed to counteract perceptions that group psychotherapy is less desirable than individual therapy and to more effectively market the benefits of group counseling services (Golden et al., 1993; Parcover et al., 2006). To fill groups with adequate numbers of clients, counseling centers may need to implement a strong internal referral system, wherein clients are directed to group interventions at intake.

The averaged data from the survey also suggest that if counselors are spending more than 10 hours per week on administrative duties, or if counseling center administrators are spending more than 20 hours per week on administrative duties, their loads exceed the norm, and the centers could look for ways to lighten administrative loads (e.g., providing secretarial assistance, increasing delegation, 
streamlining policies, practices, forms, meetings, etc.). In making this observation, we acknowledge that responsibilities and managerial structures differ widely among counseling centers, such that average data across many counseling centers may not inform the work of a particular center. However, we also believe that in some centers managerial structures may have been established arbitrarily or for historical reasons that are no longer relevant, and that such counseling centers may indeed benefit from re-structuring and streamlining administration, particularly when administrative hours replace direct service hours. Simplifying reports and procedures and working to provide effective service management should receive much more attention in the professional literature, particularly because many college counselors have not received training in organization management.

\section{Collaboration Across Campus}

College counselors generally reported regular contact with personnel from other campus offices. More than half of the participants reported having at least weekly contact with university administrators and faculty. However, some counselors reported infrequent contact, which may make it difficult to establish/maintain the close working relationships that are necessary to effectively advocate for counseling center resources (e.g., Ellingson et al., 1999). Similarly, the average of one contact per month with health/medical services or disability/accessibility services indicated by some counselors may not be sufficient to provide the kind of high quality services advocated in the literature (e.g., Stone \& Archer, 1990; Stone, Vespia, \& Kanz, 2000).

\section{Multicultural Competence}

Standards for multicultural competencies (Arredondo et al., 1996) specify that mental health professionals should collaborate with cultural experts and seek out culture-specific information when working with clients from diverse backgrounds. The fact that counselors collaborate with personnel from multicultural student services and international student services less frequently than with of any of the other campus entities considered in this survey (Table 2), with 30-48\% having no contact or 
minimal contact, suggests that counselors could do more to improve the quality of services provided for multicultural and international students (see Mori, 2000; Wright, 2000).

Where survey participants were asked how their centers adapt counseling services for multicultural clients, the most frequently reported strategy was to provide sensitivity training to current staff. Multicultural training can increase counselors' ability to work with clients of color (Smith, Constantine, Dunn, Dinehart, \& Montoya, 2006). However, multicultural counseling competence involves structural and institutional adaptations (Arredondo \& Rice, 2004) that were mentioned in only one participant's response to the question. Counselors are encouraged to consider the multiple aspects of multicultural competence (Arredondo et al., 1996; Wright, 2000) and to consider meaningful changes in policy and procedures that may be necessary to better meet the needs of all potential clients, particularly clients from racial and ethnic minority groups who are unlikely to seek traditional counseling (Davidson et al., 2004). "If counseling centers continue to function in their traditional manner, they will probably only deal with their traditional clientele” (Bishop, 1990, p. 411). Exemplary multicultural practices in counseling centers may provide useful models to emulate (e.g., Smith, Baluch, Bernabei, Robohm, \& Sheehy, 2003).

\section{Crisis Planning and Disaster Mental Health}

Most counselors (79\%) reported having some involvement in crisis planning on campus. However, much of that involvement appears to be superficial. Only 26\% of participants reported having a systematic, comprehensive plan in place to respond to crises/disasters impacting the campus. According to the 2003 National Survey of Counseling Center Directors (Gallagher et al.), only 7\% of college counseling centers even have a person designated as a "crisis counselor" or "crisis coordinator.” Therefore, an obvious initial step toward improvement in crisis/disaster counseling would be for counseling center administrators to define who is responsible for planning for and managing crises. Additional steps could include training counselors in the effective treatment of 
traumatic stress disorders, regularly reviewing the crisis/disaster plans and procedures with counseling staff and university administrators, and rehearsing a mock crisis with campus and community security and crisis response services (see also Lee \& Casey, 2004; Ottens \& Black, 2000; Schwitzer, 2003).

\section{Limitations}

In interpreting these results, several limitations of the survey data need to be considered. Specifically, the data presented here may not accurately represent the experiences of all college counselors whose primary affiliation is with the counseling profession. Even though the participants were randomly selected ACCA members, only about one-third returned completed surveys, and the respondents may differ from the general population of college counselors. For example, our data did not evaluate differences across institution size (large vs. small) or type (community college vs. university). Furthermore, survey research is problematic due to possible biases among respondents in evaluating their own work environment and to possible inaccuracy of retrospective recall. Finally, although this survey addressed several of the most pressing issues in the college counseling profession, it did not address many other issues, including the use of practicum students and interns, counselors-inresidence and residential living services, substance abuse counseling, or spiritual/existential issues that have also been discussed in the recent literature (e.g., Briggs, Apple, \& Aydlett, 2004; Johnson \& Hayes, 2003; Rawls, Johnson, \& Bartels, 2004). Future surveys can evaluate these issues and verify that the trends reported here are consistent across time and across populations.

\section{Summary}

College counselors provide a variety of services across multiple settings (Davis \& Humphrey, 2000). The results of this survey underscore the claim that the profession will need broadly experienced counselors to develop specialized skills to keep up with global trends (e.g., Bishop, 2006; Erdur-Baker et al., 2006; Marsella \& Pedersen, 2004). College counselors need to be skilled in dealing with clients with severe pathology and with those from multicultural backgrounds. They need to 
effectively plan for and manage crisis/disaster interventions, and they need to actively consult with health/medical personnel and with a number of other professionals across campus. They need to provide a variety of effective interventions besides individual counseling. In doing so, they demonstrate the utility of college counseling services to the campus community. 


\section{References}

Arredondo, P., Toporek, R., Brown, S. P., Jones, J., Locke, D. C., Sanchez, J., \& Stadler, H. (1996). Operationalization of the multicultural counseling competencies. Journal of Multicultural Counseling and Development, 24, 42-78.

Arredondo, P., \& Rice, T. M. (2004). Working from within: Contextual mental health and organizational competence. In T.B. Smith (Ed.), Practicing multiculturalism: Affirming diversity in counseling and psychology, pp. 76-96. Boston: Allyn \& Bacon.

Benton, S.A., Robertson, J.M., Tseng, W., Newton, F.B., \& Benton, S.L. (2003). Changes in counseling center client problems across 13 years. Professional Psychology: Research and Practice, 34, 66-72.

Bishop, J. B. (1990). The university counseling center: An agenda for the 1990s. Journal of Counseling \& Development, 68, 408-413.

Bishop, J. B. (2006). College and university counseling centers: Questions in search of answers. Journal of College Counseling, 9, 6-19.

Briggs, M. K., Apple, K., \& Aydlett, A. E. (2004). Spirituality and the events of September 11: A preliminary study. Counseling and Values, 48, 174-182.

Coll, K., \& Stewart, R. (2002). Collaboration between counseling services and an academic program: An exploratory study of student outcome. Journal of College Counseling, 5, 135-141.

Cooper, S. (2003). College counseling centers as internal organizational consultants to universities. Consulting Psychology Journal: Practice and Research, 55, 230-238.

Davidson, M.M., Yakushka, O.F., \& Sanford-Martens, T.C. (2004). Racial and ethnic minority clients’ utilization of a university counseling center: An archival study. Journal of Multicultural Counseling and Development, 32, 259-271. 
Davis, D. C., \& Humphrey, K. M. (Eds.). (2000). College counseling: Issues and strategies for the new millennium. Alexandria, VA: American Counseling Association.

Denzin, N. K., \& Lincoln, Y. S. (Eds.). (2000). Handbook of qualitative research (2 ${ }^{\text {nd }}$ ed.). Thousand Oaks, CA: Sage.

Ellingson, K.T., Kochenour, E.O., \& Weitzman, L. (1999). University counseling center consultation developing a faculty outreach program. Consulting Psychology Journal, 51, 31-36.

Erdur-Baker, O., Aberson, C. L., Barrow, J. C. \& Draper, M. R. (2006). Nature and severity of college students’ psychological concerns: A comparison of clinical and nonclinical national samples. Professional Psychology: Research and Practice, 37, 317-323.

Gallagher, R., Zhang, B., \& Taylor, R. (2003). National survey of counseling center directors. Alexandria, VA: International Association of Counseling Services.

Golden, B.R., Corazzini, J.G., \& Grady, P. (1993). Current practice of group therapy at university counseling centers: A national survey. Professional Psychology: Research and Practice, 24, 228-230.

Guinee, J.P., \& Ness, M.E. (2000). Counseling centers of the 1990s: Challenges and changes. The Counseling Psychologist, 28, 267-280.

Hodges, S. (2001). University counseling centers at the twenty-first century: Looking forward, looking back. Journal of College Counseling, 4, 161-173.

Johnson, C.V., \& Hayes, J.A. (2003). Troubled spirits: Prevalence and predictors of religious and spiritual concerns among university students and counseling center clients. Journal of Counseling Psychology, 50, 409-418.

Kiracofe, N. M. (1993). Changing demands on counseling centers: Problems and possibilities. Journal of College Student Psychotherapy, 7, 69-83. 
Lee, R., \& Casey, D. (Eds.) (2004). Crisis \& trauma in colleges and universities. Ellicott City, MD: Chevron.

Marsella, A. J., \& Pedersen, P. (2004). Internationalizing the counseling psychology curricula: Toward new values, competencies, and directions. Counseling Psychology Quarterly, 17, 413-423.

McRoberts, C., Burlingame, G. M., Hoag, M. J. (1998). Comparative efficacy of individual and group psychotherapy: A meta-analytic perspective. Group Dynamics, 2, 101-117.

Mori, S. (2000). Addressing the mental health concerns of international students. Journal of Counseling \& Development, 78, 137.

Parcover, J. A., Dunton, E. C., Gehlert, K. M. (2006). Getting the most from group counseling in college counseling centers. Journal for Specialists in Group Work, 31, 37-49.

Ottens, A., \& Black, L. L. (2000). Crisis interventions at college counseling centers. In A.R. Roberts (Ed.), Crisis intervention handbook: Assessment, treatment, and research (pp. 152-173). New York: Oxford University Press.

Rawls, D. T., Johnson, D., \& Bartels, E. (2004). The Counselor-in-Residence program: Reconfiguring support services for a new millennium. Journal of College Counseling, 7, 162-169.

Rudd, M. D. (2004). University counseling centers: Looking more and more like community clinics. Professional Psychology: Research and Practice, 35, 316-317.

Schwitzer, A.M. (2003). A framework for college counseling responses to large scale traumatic incidents. Journal of College Student Psychotherapy, 18(2), 49-66.

Smith, L., Baluch, S., Bernabei, S., Robohm, J., \& Sheehy, J. (2003). Applying a social justice framework to college counseling center practice. Journal of College Counseling, 6, 3-13.

Smith, T. B., Constantine, M. G., Dunn, T. W., Dinehart, J., \& Montoya, J. A. (2006). Multicultural education in the mental health professions: A meta-analytic review. Journal of Counseling Psychology, 53, 132-145. 
Spriggs, M. (2005, August). ACCA raises call for advocacy efforts. Counseling Today, p. 30.

Stone, G. L. (1988). The heroic syndrome. Journal of Counseling and Development, 67, 108.

Stone, G. L., \& Archer, J. (1990). College and university counseling centers in the 1990s: Challenges and limits. The Counseling Psychologist, 18, 539-607.

Stone, G.L., Vespia, K.M., \& Kanz, J.E. (2000). How good is mental health care on college campuses? Journal of Counseling Psychology, 47, 498-510.

Wright, D. J. (2000). College counseling and the needs of multicultural students. In D. C. Davis, \& K. M. Humphrey (Eds.), College counseling: Issues and strategies for the new millennium (pp. 153-168). Alexandria, VA: American Counseling Association. 
Table 1

Time Spent by Counselors and Administrators on Service and Administrative Activities.

\begin{tabular}{|c|c|c|c|}
\hline Activity & $\begin{array}{l}\text { Counseling Center } \\
\text { Counselors }(n=50) \\
\qquad M \quad(S D)\end{array}$ & $\begin{array}{l}\text { Counseling Center } \\
\text { Administrators }(n=58) \\
\qquad M(S D)\end{array}$ & $\begin{array}{l}\text { Total } \\
(N=108) \\
M \quad(S D)\end{array}$ \\
\hline Direct services (\% of work week) & $62(18)$ & $45(21)$ & $53(21)$ \\
\hline Indirect services (\% of work week) & 19 (12) & $18(7)$ & $18(10)$ \\
\hline Administration (\% of work week) & $13(12)$ & $27(22)$ & 21 (19) \\
\hline Other activities (\% of work week) & $7 \quad(6)$ & 11 (9) & $9(8)$ \\
\hline Individual counseling hours/week & $23.4(12)$ & $15.5(8)$ & $19(11)$ \\
\hline Group counseling hours/week & $.7(1)$ & $1.0(1)$ & $.9(14)$ \\
\hline Outreach programs hours/week & $2.4(4)$ & $2.8(3)$ & $2.6(3)$ \\
\hline
\end{tabular}


Table 2.

Frequency of work with personnel from other campus offices/departments.

\begin{tabular}{lcclll}
\hline & Mean & SD & $\begin{array}{l}\text { Average } \\
\text { frequency } \\
\text { of contact }\end{array}$ & $\begin{array}{l}\text { \% having } \\
\text { no or } \\
\text { minimal } \\
\text { contact }\end{array}$ & $\begin{array}{l}\text { \% having } \\
\text { at least } \\
\text { weekly } \\
\text { contact }\end{array}$ \\
\hline $\begin{array}{lcccc}\text { Professors/Instructors } \\
\text { University Administration }\end{array}$ & 5.3 & 1.4 & Bi-monthly & 4 & 51 \\
Academic Advising & 5.1 & 1.5 & Bi-monthly & 10 & 53 \\
Disability/Accessibility Services & 4.4 & 1.7 & Monthly & 17 & 33 \\
Health/Medical Center & 4.3 & 2.0 & Monthly & 28 & 28 \\
Multicultural Student Services & 4.1 & 1.9 & Monthly & 30 & 30 \\
International Student Services & 3.4 & 1.7 & Quarterly & 41 & 16 \\
\hline
\end{tabular}


Table 3

Content Analysis of Responses to Seven Open-ended Questions about Issues Affecting Counseling Centers.

Theme

$$
\text { Question }
$$

\% responses

\section{Describe how your counseling center meets increasing demands for clinical services.}

Advocate school administration to hire additional counselors

Use waiting list

Impose session limits

Take on the additional caseload, disregarding other needs

Outsource: refer clients to other services

Use group counseling sessions to accommodate more clients

Leave caseload up to individual counselors: no policy changes

Caseload demand is not an issue
$26 \%$

$17 \%$

$16 \%$

$14 \%$

$10 \%$

$9 \%$

$4 \%$

$4 \%$

\section{Describe how your counseling center increases support for counseling center services.}

Schedule a meeting to inform them of counseling center issues/activities

Take no action

Generate statistics, share research articles, or provide an annual report

Involve counselors in student activities/organizations to increase their visibility
$33 \%$

$30 \%$

$23 \%$

$14 \%$

Describe how your counseling center has adapted services to multicultural populations.

Provide professional development training for counselors and staff

Hire staff/counselors of color

Consult with personnel from multicultural/international student services

Provide outreach services to specific groups on campus
$44 \%$

$22 \%$

$22 \%$

$11 \%$ 


\section{Describe how your counseling center meets crisis/disaster mental health incidents/needs.}

The campus/center has a plan in place (vague responses, few specifics provided) 33\%

A well defined program/team in the center is available for crises (on call) 26\%

Professional development training to handle crisis/disaster needs is given to staff $19 \%$

The center has done nothing $\quad 4 \%$

Some other campus entity handles crisis/disaster incidents/needs $\quad 7 \%$

How has student use of psychotropic medication affected your counseling center, if at all?

Increased consultation with medical professionals regarding

medication/monitoring

$30 \%$

More students are better able to manage and remain in school with medications $\quad 17 \%$

Greater severity of mental health conditions on college campuses than in the past $13 \%$

Some students seek a “quick-fix,” limiting their engagement with counseling $\quad 9 \%$

Hiring medical professional to work in the counseling center $\quad 7 \%$

Students come to college more aware of mental health issues than in the past $\quad 7 \%$

Intake and evaluations more thoroughly assess medication history $\quad$ 7\%

Many students lack money/insurance to pay for needed medications $\quad$ 7\%

Student medication use has had no impact upon our counseling center $\quad 4 \%$

What aspects of graduate education could have better prepared you for work in a counseling center?

Multicultural training, increasing multicultural competence/skills $\quad 19 \%$

Applied clinical experience: diagnostic training, group therapy, brief therapy $\quad 19 \%$

Administration/management; business, accounting, and organizational skills $\quad 15 \%$ 
Disaster planning and crisis management

Spirituality and religious issues

$12 \%$

Content specific to understanding higher education

(e.g., student life, residential life)

$12 \%$

Legal and ethical issues

$8 \%$

Substance abuse counseling

$4 \%$

What is the one thing that you most desire to improve about your counseling center?

Additional resources (funding, office space, computers, assessment instruments) $\quad 30 \%$

Additional numbers of counselors on staff

$28 \%$

Greater visibility/credibility on campus and in the community $\quad 20 \%$

Improved professionalism/collegiality of counselors in the center $\quad 11 \%$

Improved service provision (more group counseling, crisis planning, etc.) $\quad 9 \%$

Additional time available for service provision $\quad 3 \%$ 